\title{
Education on popular diseases to improve the quality of life for the people of Landungsari Village, Malang Regency
}

\section{Edukasi penyakit populer untuk meningkatkan kualitas hidup masyarakat Desa Landungsari, Kabupaten Malang}

\author{
Arif Kusuma Firdaus', Ahmad Rizki Maulana', Fatita Rachma Laudira1, Novitasari Agus Saputri², \\ Ulya Zhafirah Wardah', Waldiyansyah Rizkyfi Makky' \\ ${ }^{7}$ Fakultas Kedokteran Universitas Muhammadiyah Malang \\ J. Bendungan Sutami No.188, Malang, 65145, Indonesia \\ ${ }^{2}$ Fakultas Ekonomi dan Bisnis Universitas Muhammadiyah Malang \\ Jl. Raya Tlogomas No. 246, Malang, 65144. Indonesia
}

\begin{abstract}
ARTICLE INFO:
Received: 2021-07-27

Revised: 2021-09-14

Accepted: 2021-12-02

Keywords:

Education, Noncommunicable diseases, Society

\section{ABSTRACT}

Diabetes mellitus, heart disease, and joint disease are non-communicable diseases that are popular in the community. This disease is mostly suffered by the age group above 15 years which causes various complications, even death. The purpose of this program is to increase public knowledge and understanding of diseases, especially regarding how to prevent them, so that they can help improve the quality of public health. The method of community service activities is carried out by means of online and offline education and socialization which is carried out in three stages. The first stage is the preparation of activities, the second stage is the implementation of the activities, and the third stage is the evaluation and report generation. The results showed increased knowledge and understanding of the community about popular diseases which is marked by an increase in the posttest questionnaire score. Increase public knowledge and understanding of popular diseases that exist in the community, especially how to prevent disease in the hope of improving the quality of public health.
\end{abstract}

(C) 2022 Abdimas: Jurnal Pengabdian Masyarakat Universitas Merdeka Malang This is an open access article distributed under the CC BY-SA 4.0 license (https://creativecommons.org/licenses/by-sa/4.0/)

How to cite: Firdaus, A. K., Maulana, A. R., Laudira, F. R., Saputri, N. A., Wardah, U. Z., \& Makky, W. R. (2022). Education on popular diseases to improve the quality of life for the people of Landungsari Village, Malang Regency. Abdimas: Jurnal Pengabdian Masyarakat Universitas Merdeka Malang, 7(1), 131-138. https://doi.org/10.26905/abdimas.v7i1.6115

\section{PENDAHULUAN}

Penyakit Tidak Menular (PTM) atau Non Communicable Disease adalah penyebab kematian utama secara global, dan salah satu penyebab utama tantangan kesehatan abad ke-21. Berdasarkan profil data PTM WHO pada tahun 2016, PTM merupakan penyebab kematian terbesar dunia yakni $71 \%$ dalam 57 juta kematian global, dengan persentase 31\% penyakit kardiovaskular, 3\% diabetes, dan 15\% PTM 
ABDIMAS: Jurnal Pengabdian Masyarakat Universitas Merdeka Malang

Volume 7, No 1, February 2022: 131-138

lain (Damasceno, 2016). PTM dapat berupa asma, kanker, diabetes, penyakit jantung, hipertensi, stroke, penyakit gagal ginjal kronis, penyakit sendi, dan sebagainya (Kemenkes RI, 2018).

Diabetes melitus (DM) adalah sekelompok penyakit metabolik yang ditandai dengan hiperglikemia kronis akibat kelainan sekresi insulin, kerja insulin, atau keduanya (Kharroubi, 2015). DM sendiri terbagi menjadi 2 tipe, yaitu DM tipe 1 dan DM tipe 2 (Olokoba et al., 2012). Menurut International Diabetes Federation (IDF), pada tahun 2019, 463 juta orang dewasa berusia antara 20 hingga 79 tahun hidup dengan diabetes. Jumlah tersebut kemungkinan akan meningkat hingga 700 juta pada tahun 2045 (Galicia-Garcia et al., 2020). Diabetes mellitus dapat menyebabkan berbagai komplikasi penyakit berupa nefropati diabetik yang merupakan kerusakan pada tubulus ginjal, retinopati diabetik yang mempengaruhi penglihatan, serta Neuropati Perifer Diabetik (NPD) yang dapat berkembang menjadi ulkus diabetik pada kaki. Selain itu, dapat terjadi Peripheral Artery Disease (PAD) yang merupakan komplikasi umum dan komorbiditas dari DM (Papatheodorou et al., 2018).

Peningkatan kadar asam urat dalam darah (hiperurisemia), yaitu jika kadar asam urat darah lebih dari 7,5 mg/dl (Damayanti D, 2012). Hiperurisemia yang lama dapat merusak sendi, jaringan lunak, dan ginjal. Hiperurisemia bisa juga tidak menampakkan gejala klinis/asimtomatis (Misnadiarly, 2008). Prevalensi penyakit asam urat di Indonesia berdasarkan Riskesdas 2018 didapatkan persentase sebesar 7,3\%. Jawa timur dengan presentase 6,72\% dari penduduk di atas usia 15 tahun (Kemenkes Rl, 2018). Hiperurisemia disebabkan oleh dua faktor utama, yaitu meningkatnya produksi asam urat dalam tubuh yang disebabkan karena leukimia atau kanker darah yang mendapat terapi sitostatika dan kurangnya pengeluaran asam urat melalui ginjal (gout renal) akibat kerusakan dari ginjal. Faktor lain yang dapat mempengaruhi adalah nutrisi, obat, obesitas, dan usia (Rothenbacher et al., 2011).

Peningkatan kadar kolesterol LDL (Low Density Lipid) darah merupakan salah satu faktor resiko utama dari penyakit kardiovaskular selain diabetes dan hipertensi. Berdasarkan Riskesdas oleh Kemenkes RI pada tahun $2018,10 \%$ dari 713.783 responden yang diteliti dari 34 provinsi menderita stroke, di Jawa timur sendiri persentasenya meningkat menjadi $12,4 \%$ responden penderita stroke yang faktor resiko utama dari penyakit ini adalah peningkatan kadar kolesterol LDL (Kemenkes RI, 2018). Kadar kolesterol yang tinggi dapat meningkatkan tekanan darah, menyebabkan gejala-gejala hipertensi seperti pusing, lemas, dan lain-lain. Selain itu juga dapat meningkatkan deposit lemak di beberapa bagian tubuh, sehingga menyebabkan peningkatan berat badan dan menyebabkan penyakit liver. Kadar kolesterol LDL yang tinggi juga dapat menyebabkan pembentukan plak di pembuluh darah. Jika hal ini terjadi pada pembuluh darah vital seperti arteri koronaria pada jantung atau arteri-arteri di otak dapat berakibat fatal, seperti stroke, hingga serangan jantung yang dapat menyebabkan kematian mendadak (Menet, 2018).

Penyebab tingginya prevalensi PTM seperti yang dijelaskan di atas dicirikan oleh banyak gaya hidup yang tumpang tindih dan faktor risiko klinis, seperti obesitas, kurangnya aktivitas fisik, tekanan darah tinggi, gangguan toleransi glukosa, kolesterol tinggi, diet tidak sehat, merokok, dan konsumsi alkohol berlebih yang telah diidentifikasi oleh WHO sebagai faktor risiko mendasar pada sebagian besar PTM yang dapat dicegah (Peters et al., 2018). Edukasi dan sosialisasi yang tepat mengenai pencegahan PTM yang populer di masyarakat terutama penyakit jantung, diabetes, dan penyakit sendi menjadi tujuan utama dikarenakan berdasarkan wawancara dengan masyarakat sekitar ketiga penyakit tersebut kerap diderita oleh masyarakat setempat sehingga diperlukan pemahaman dari setiap individu mengenai hal ini, mulai dari perjalanan, penyebab, tatalaksana terkait penyakit agar dapat melakukan strategi pencegahan dan penanganan dari kondisi yang paling sesuai dengan keadaan masing-masing (Arsana et al., 2019). 
Dilakukan kegiatan pengabdian di Desa Landungsari, Kecamatan Dau, Kabupaten Malang dikarenakan tingginya angka penyakit diabetes, asam urat, dan kolesterol di masyarakat Jawa Timur berdasarkan Riset Kesehatan Dasar tahun 2018, sehingga untuk meningkatkan pengetahuan dan kesadaran masyarakat terutama usia dewasa muda dan tua agar mengetahui betapa pentingnya menjaga pola hidup untuk mencegah PTM dan harapannya dapat membantu masyarakat untuk terhindar dari PTM dengan tujuan akhir dapat meningkatkan kualitas hidup di semua kelompok usia (Kemenkes RI, 2018). Artikel ini membahas salah satu kegiatan pengabdian masyarakat berupa edukasi dan sosialisasi secara daring maupun luring terkait penyakit-penyakit populer yang banyak diderita oleh masyarakat dengan tiga tahapan, yaitu tahap pertama yakni persiapan kegiatan, tahap kedua adalah pelaksanaan kegiatan, dan tahap ketiga yakni evaluasi dengan pretest dan posttest. Program pengabdian ini bertujuan untuk meningkatkan kualitas hidup masyarakat di Desa Landungsari, Kecamatan Dau, Kabupaten Malang.

\section{METODE}

\section{Metode pendekatan}

Berdasarkan data Riskesdas oleh Kemenkes RI tahun 2018 menunjukkan tingginya prevalensi penyakit tidak menular, seperti diabetes, asam urat, dan penyakit yang disebabkan kolesterol yang tinggi, seperti stroke dan lainnya. Sebagai upaya menangani permasalahan kesehatan tersebut maka solusi yang ditawarkan berupa: (1) Memberikan sosialisasi kepada masyarakat mengenai penyakit populer di masyarakat yakni diabetes, asam urat, dan penyakit jantung koroner. Sosialisasi berupa definisi, faktor penyebab, gejala, dan terutama cara pencegahan penyakit tersebut; (2) Penempelan poster mengenai asam urat, diabetes, dan kolesterol. Sasaran dalam kegiatan ini adalah masyarakat yang tinggal di Desa Landungsari, Dau, Kabupaten Malang dan sebagai tambahan yakni takmir masjid sebagai tokoh agama yang memegang peranan penting yang berada di daerah tersebut.

\section{Kerangka pemecahan masalah}

Berikut merupakan gambar yang menggambarkan kerangka pemecahan masalah dalam upaya promotif dan preventif mengenai penyakit populer oleh Kelompok 82 Gelombang 9.

\begin{tabular}{|c|c|c|c|c|}
\hline $\begin{array}{c}\text { Masalah Mitra: } \\
\text { Tingginya angka } \\
\text { penyakit diabetes, } \\
\text { asam urat, dan } \\
\text { kolesterol di } \\
\text { masyarakat }\end{array}$ & $\begin{array}{c}\text { Selakukan kegiatan edukasi } \\
\text { dengan melakukan tiga tahapan } \\
\text { yaitu persiapan, pelaksanaan, dan } \\
\text { evaluasi. Edukasi dilakukan } \\
\text { dengan cara door to door ke } \\
\text { masyarakat dan ke takmir masjid } \\
\text { selaku tokoh agama di lingkungan } \\
\text { tersebut. }\end{array}$
\end{tabular}

Gambar 1. Kerangka pemecahan masalah

\section{Realisasi pemecahan masalah}

Pemecahan masalah dalam kegiatan dibagi dalam tiga tahapan yakni tahapan persiapan, tahapan pelaksanaan, dan tahapan akhir. Dalam tahapan persiapan yang kami lakukan adalah survei lokasi dan 
ABDIMAS: Jurnal Pengabdian Masyarakat Universitas Merdeka Malang

Volume 7, No 1, February 2022: 131-138

meminta izin kepada pihak yang berwenang di daerah tempat kegiatan berlangsung untuk melakukan kegiatan, penempelan poster, dan pembuatan kuesioner. Dalam tahapan pelaksanaan yang kami lakukan adalah memberikan kuesioner berisi pertanyaan sebelum dan sesudah edukasi. Edukasi yang kami lakukan kepada masyarakat dengan menggunakan poster, penempelan poster, dan dokumentasi selama kegiatan berlangsung. Dalam kegiatan tahapan akhir yang kami lakukan adalah evaluasi dan pembuatan laporan kegiatan.

\section{Metode kegiatan dan evaluasi}

Metode kegiatan yang digunakan adalah dengan melakukan sosialisasi oral dengan media poster mengenai penyakit diabetes, asam urat, dan kolesterol. Untuk evaluasi dari kegiatan ini dilakukan pretest dan post-test sebagai bahan acuan tingkat pemahaman masyarakat terhadap materi yang diberikan. Pengisian kuesioner oleh responden dilakukan sebelum diberikan edukasi dan setelah diberikan edukasi. Kuesioner mengandung 6 butir pertanyaan dan responden diminta untuk memberikan penjelasan singkat dari pertanyaan yang diajukan. Setiap poin yang dijawab secara benar akan bernilai 10 dan jika poin yang dijawab secara salah akan bernilai 0 .

Tabel 1. Pertanyaan kuesioner

\begin{tabular}{ll}
\hline \multicolumn{1}{c}{ Pertanyaan } & Jawaban \\
\hline 1. & Apakah yang dimaksud dengan penyakit diabetes? \\
2. & Apa saja gejala seseorang terkena diabetes? \\
3. Apakah yang dimaksud dengan penyakit asam urat? \\
4. Apa saja penyebab seseorang terkena penyakit asam urat? \\
5. Apakah yang dimaksud dengan penyakit kolesterol? \\
6. & Bagaimana cara mencegah terkena penyakit kolesterol? \\
\hline
\end{tabular}

Tabel 2. Jenis kegiatan sosialisasi

\begin{tabular}{|c|c|c|}
\hline Bidang & Rencana Kerja & Target Luaran \\
\hline Kegiatan Daring & $\begin{array}{l}\text { 1. Pembuatan materi sosialisasi } \\
\text { 2. Sosialisasi melalui media sosial }\end{array}$ & $\begin{array}{l}\text { 1. Materi sosialisasi berupa poster } \\
\text { 2. Postingan di media sosial }\end{array}$ \\
\hline Kegiatan Luring & $\begin{array}{l}\text { 1. Perizinan ke kantor desa } \\
\text { 2. Pemasangan poster } \\
\text { 3. Presentasi oral kepada masyarakat } \\
\text { 4. Evaluasi kegiatan }\end{array}$ & $\begin{array}{l}\text { 1. Mendapat izin dari kantor desa untuk } \\
\text { melakukan kegiatan di desa tersebut } \\
\text { 2. Poster tertempel di lingkungan } \\
\text { masyarakat } \\
\text { 3. Sosialisasi secara door to door } \\
\text { 4. Peningkatan pemahaman masyarakat } \\
\text { ditandai dengan peningkatan skor } \\
\text { kuesioner sebelum dan sesudah edu- } \\
\text { kasi }\end{array}$ \\
\hline
\end{tabular}

\section{HASIL DAN PEMBAHASAN}

Kegiatan dilakukan dalam tiga tahap, yaitu tahap persiapan, tahap pelaksanaan, dan tahap akhir. Pada tahap persiapan yang dilakukan adalah proses perizinan kepada pihak desa, kemudian persiapan materi sosialisasi, dan pembuatan media pendukung proses sosialisasi. Tahap ini dilaksanakan selama 2 minggu, yakni sejak tanggal 8 Juni 2021 hingga 22 Juni 2021. 

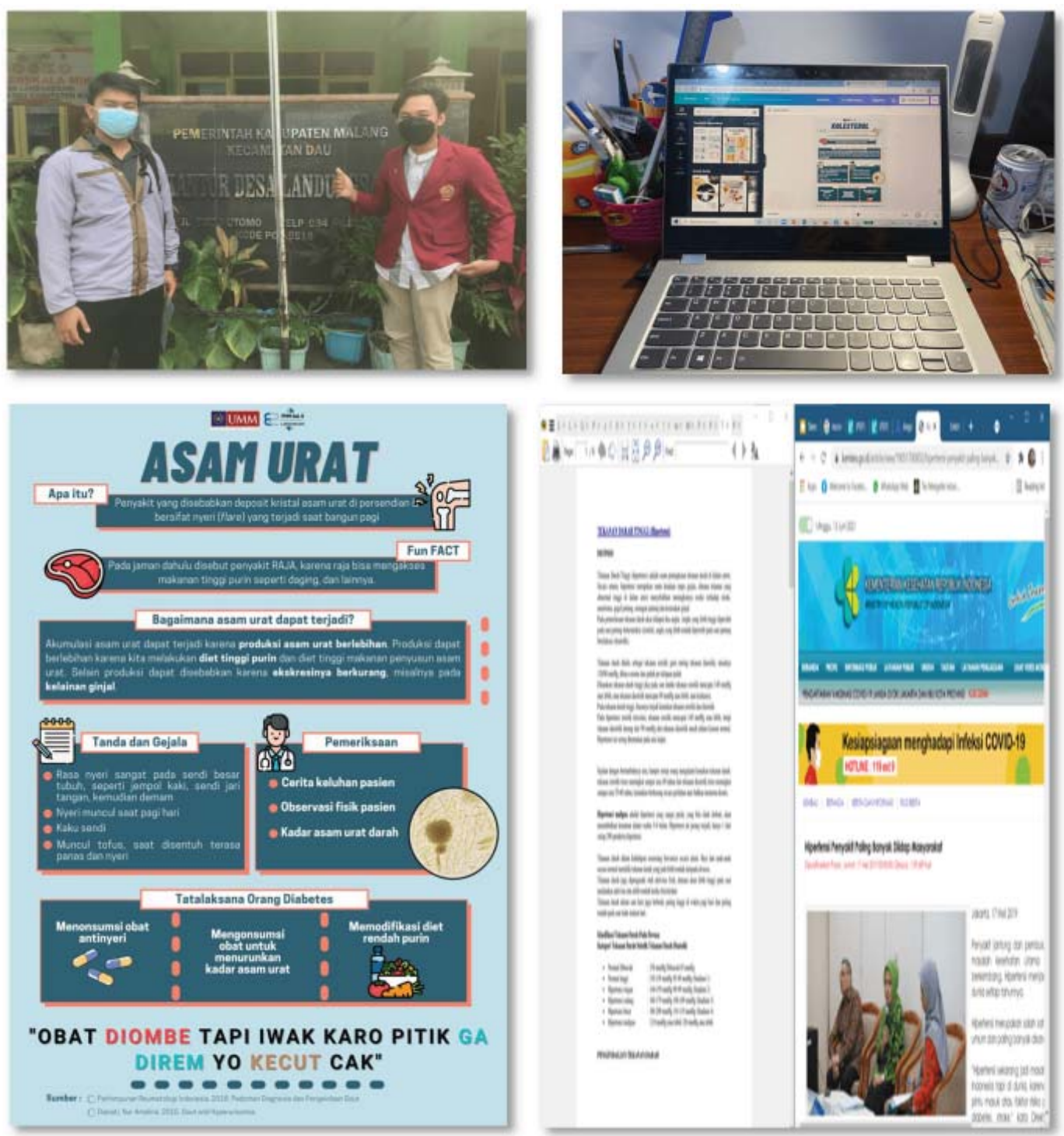

Gambar 2. Kunjungan ke kantor desa dalam rangka meminta izin kegiatan

Gambar 3. Proses pembuatan poster

Gambar 4. Persiapan materi sosialisasi dan konten edukasi di media sosial

Pada tahap kedua, pelaksanaan sosialisasi dilakukan secara luring dengan mendatangi rumahrumah warga, pelaksanaan kegiatan dilakukan dengan alat bantu berupa poster dan kertas lembar evaluasi pre-test dan post-test, serta gawai untuk mendokumentasikan kegiatan yang berlangsung. Pemasangan poster dilakukan di tempat umum yang sering didatangi dan mudah dilihat oleh warga, tempat yang dipilih pada program ini adalah mading masjid di daerah sekitar lokasi pengabdian masyarakat berlangsung. Terdapat 4 masjid/musholla besar yang dipilih sebagai lokasi pemasangan poster. Pelaksanaan sosialisasi secara daring dilakukan dengan mengupload konten edukasi dan materi sosialisasi berupa penjelasan mengenai penyakit yang populer di masyarakat pada akun media sosial berupa Instagram. 
ABDIMAS: Jurnal Pengabdian Masyarakat Universitas Merdeka Malang Volume 7, No 1, February 2022: 131-138
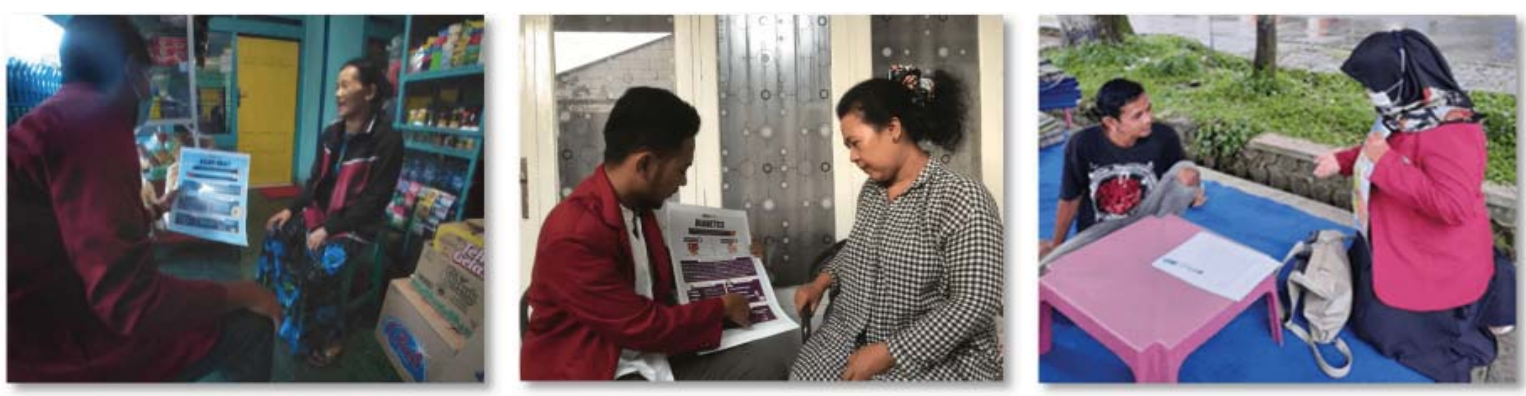

Gambar 5. Proses sosialisasi dengan menggunakan media poster
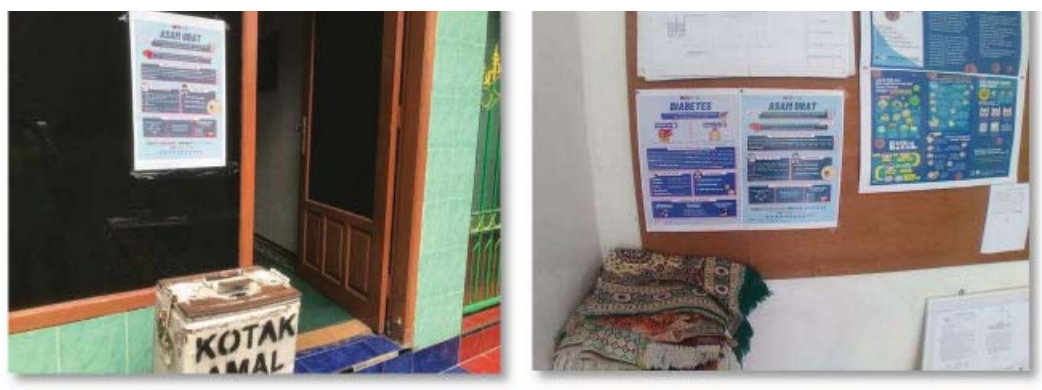

Gambar 6. Penempelan poster di tempat umum
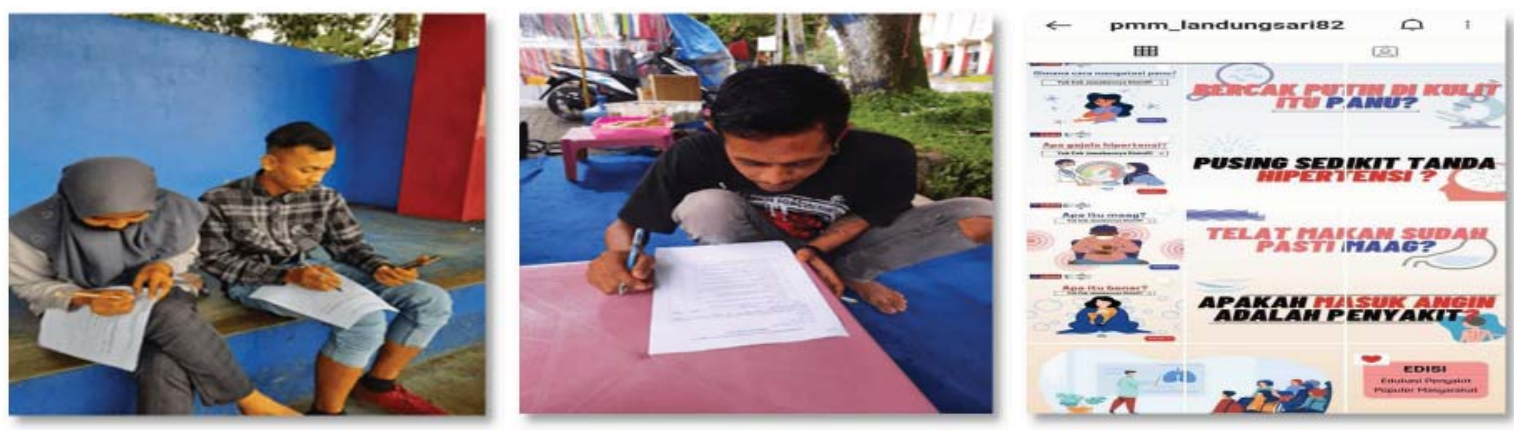

Gambar 7. Pengambilan data evaluasi melalui pre-test dan post-test

Gambar 8. Pelaksanaan edukasi secara daring

Pada tahap kegiatan ketiga kami melakukan pembuatan laporan akhir, evaluasi kegiatan, dan refleksi diri. Evaluasi dilakukan untuk mengetahui apakah kegiatan yang sudah dilakukan mencapai target yang diharapkan atau tidak.

Tabel 3. Distribusi pengetahuan masyarakat tentang penyakit populer sebelum dan sesudah edukasi

\begin{tabular}{|c|c|c|c|c|c|}
\hline \multirow{2}{*}{\multicolumn{2}{|c|}{ Pernyataan }} & \multicolumn{2}{|c|}{ Benar Sebelum } & \multicolumn{2}{|c|}{ Benar Sesudah } \\
\hline & & \multirow{2}{*}{$\begin{array}{l}\mathbf{N} \\
13\end{array}$} & \multirow{2}{*}{$\begin{array}{c}\% \\
86,7\end{array}$} & \multirow{2}{*}{$\begin{array}{c}\mathbf{N} \\
15\end{array}$} & \multirow{2}{*}{$\begin{array}{c}\% \\
100\end{array}$} \\
\hline 1. & Apakah yang dimaksud dengan penyakit diabetes? & & & & \\
\hline 2. & Apa saja gejala seseorang terkena diabetes? & 8 & 53,3 & 12 & 80 \\
\hline 3. & Apakah yang dimaksud dengan penyakit asam urat? & 10 & 66,7 & 13 & 86,7 \\
\hline 4. & Apa saja penyebab seseorang terkena penyakit asam urat? & 7 & 46,7 & 12 & 80 \\
\hline 5. & Apakah yang dimaksud dengan penyakit kolesterol? & 11 & 73,3 & 14 & 93,3 \\
\hline 6. & Bagaimana cara mencegah terkena penyakit kolesterol? & 11 & 73,3 & 13 & 86,7 \\
\hline
\end{tabular}


Education on popular diseases to improve the quality of life for the people of Landungsari Village, Malang Regency Arif Kusuma Firdaus, Ahmad Rizki Maulana, Fatita Rachma Laudira, Novitasari Agus Saputri, Ulya Zhafirah Wardah, Waldiyansyah Rizkyfi Makky

Tabel 4. Distribusi nilai pengetahuan masyarakat tentang penyakit populer sebelum dan sesudah edukasi

\begin{tabular}{cccccccc}
\hline $\begin{array}{c}\text { Nilai Mini- } \\
\text { mum Pre }\end{array}$ & $\begin{array}{c}\text { Nilai Maksi- } \\
\text { mum Pre }\end{array}$ & $\begin{array}{c}\text { Total } \\
\text { Nilai Pre }\end{array}$ & $\begin{array}{c}\text { Rata- } \\
\text { Rata Nilai } \\
\text { Pre }\end{array}$ & $\begin{array}{c}\text { Nilai Mini- } \\
\text { mum Post }\end{array}$ & $\begin{array}{c}\text { Nilai Maksi- } \\
\text { mum Post }\end{array}$ & $\begin{array}{c}\text { Total Nilai } \\
\text { Post }\end{array}$ & $\begin{array}{c}\text { Rata-Rata } \\
\text { Nilai Post }\end{array}$ \\
\hline 30 & 50 & 600 & 40 & 40 & 60 & 790 & 52,67 \\
\hline
\end{tabular}

Berdasarkan pada Tabel 3 menunjukkan bahwa adanya peningkatan jumlah responden menjawab benar pada masing-masing poin pertanyaan. Pada Tabel 4 juga menunjukkan adanya peningkatan nilai minimum pre-test yang semula 30 menjadi 40 pada post-test, nilai maksimum yang semula 50 pada pretest menjadi 60 pada post-test, dan rata-rata nilai pre-test yakni 40 menjadi 52,67 pada post-test yang mana mendekati nilai sempurna 60 . Setelah edukasi, target yang diharapkan telah tercapai yang mana ditandai dengan adanya peningkatan pengetahuan masyarakat mengenai penyakit populer di masyarakat. Sesuai dengan penelitian yang dilakukan (Martini et al., 2020), bahwa kegiatan sosialisasi edukasi menggunakan media efektif dapat menunjukkan perbedaan yang bermakna berupa peningkatan pengetahuan dan pemahaman masyarakat. Kegiatan edukasi sebagai tindakan promotif dan preventif diharapkan dapat membantu meningkatkan pengetahuan dan pemahaman masyarakat dengan begitu dapat membantu mencegah terjadinya penyakit dan meningkatkan kualitas kesehatan masyarakat.

\section{SIMPULAN DAN SARAN}

Kegiatan pengabdian masyarakat ini dilakukan bertujuan sebagai tindakan promotif dan preventif dengan menggunakan metode edukasi dan sosialisasi kepada masyarakat mengenai penyakit populer yang ada. Oleh karena itu, diharapkan dapat meningkatkan pengetahuan dan pemahaman masyarakat agar dapat meningkatkan kualitas kesehatan masyarakat. Dari hasil kegiatan, berupa sosialisasi secara langsung dengan media poster, pemasangan poster edukasi, dan edukasi secara daring melalui berbagai platform media sosial online didapatkan pengabdian yang dilakukan dapat meningkatkan pengetahuan dan pemahaman masyarakat mengenai penyakit populer yang ditandai dengan adanya peningkatan nilai skor kuesioner post-test dibandingkan dengan nilai skor pre-test. Sehingga dapat terwujudkan kualitas kesehatan masyarakat yang baik.

Kegiatan pengabdian masyarakat berikutnya sebaiknya melibatkan pemerintah desa secara langsung, organisasi-organisasi kepemudaan, dan tenaga kesehatan di daerah setempat, sehingga masyarakat bisa mendapat manfaat yang optimal dan tepat sesuai dengan kebutuhan di lokasi tersebut. Sebaiknya program edukasi dan sosialisasi penyakit di masyarakat dapat ditindaklanjuti melalui kerjasama dengan mitra-mitra lain atau pihak-pihak lain di luar institusi, dengan tema penyakit yang berbeda dan dapat dilaksanakan secara berkala agar dapat terus menerus menambah wawasan masyarakat mengenai cara pencegahan penyakit dengan begitu dapat menurunkan angka kejadian penyakit dan meningkatkan kualitas kesehatan masyarakat.

\section{DAFTAR PUSTAKA}

Arsana, P. M., Rosandi, R., Manaf, A., Budhiarta, A., Permana, H., Sucipta, K. W., ... \& Suhartono, T. (2019). Pedoman pengelolaan dislipidemi di Indonesia 2019. Pb. Perkeni. doi, 10.

Damasceno, A. (2016). Noncommunicable disease. In The Heart of Africa: Clinical Profile of an Evolving Burden of Heart Disease in Africa, 155-157. https://doi.org/10.1002/9781119097136.part5 
ABDIMAS: Jurnal Pengabdian Masyarakat Universitas Merdeka Malang

Volume 7, No 1, February 2022: 131-138

Damayanti, D. (2012). Mencegah dan mengobati asam urat. Yogyakarta: Araska.

Galicia-Garcia, U., Benito-Vicente, A., Jebari, S., Larrea-Sebal, A., Siddiqi, H., Uribe, K. B., Ostolaza, H., \& Martín, C. (2020). Pathophysiology of type 2 diabetes mellitus. International Journal of Molecular Sciences, 21(17), 1-34. https://doi.org/10.3390/ijms21176275

Kemenkes RI. (2018). Hasil riset kesehatan dasar tahun 2018. Kementrian Kesehatan RI, 53(9), 16891699.

Kharroubi, A. T. (2015). Diabetes mellitus: The epidemic of the century. World Journal of Diabetes, 6(6), 850. https://doi.org/10.4239/wjd.v6.i6.850

Martini, M., Putra, G. N. W., Aryawan, K. Y., \& Widiarta, G. B. (2020). Sosialisasi pencegahan Covid19 dengan pelaksanaan health education kepada para pedagang menggunakan media pembelajaran: leaflet dalam meningkatkan pengetahuan tentang pencegahan COVID-19 di Pasar Benyuning Buleleng. In Proc. Senadimas Undiksha, 677-682.

Menet, R., Bernard, M., \& EIAli, A. (2018). Hyperlipidemia in stroke pathobiology and therapy: Insights and perspectives. Frontiers in physiology, 9, 488. https://doi.org/10.3389/fphys.2018.00488

Misnadiarly. (2008). Mengenal Penyakit Artritis. Jakarta: Badan Litbangkes.

Olokoba, A. B., Obateru, O. A., \& Olokoba, L. B. (2012). Type 2 diabetes mellitus: A review of current trends. Oman Medical Journal, 27(4), 269-273. https://doi.org/10.5001/omj.2012.68

Papatheodorou, K., Banach, M., Bekiari, E., Rizzo, M., \& Edmonds, M. (2018). Complications of diabetes 2017. Journal of Diabetes Research, 2018, 10-13. https://doi.org/10.1155/2018/3086167

Peters, R., Ee, N., Peters, J., Beckett, N., Booth, A., Rockwood, K., \& Anstey, K. J. (2019). Common risk factors for major noncommunicable disease, a systematic overview of reviews and commentary: The implied potential for targeted risk reduction. Therapeutic advances in chronic disease, 10, 1-14.

Rothenbacher, D., Primatesta, P., Ferreira, A., Cea-Soriano, L., \& Rodríguez, L. A. G. (2011). Frequency and risk factors of gout flares in a large population-based cohort of incident gout. Rheumatology, 50(5), 973-981. https://doi.org/10.1093/rheumatology/keq363 